\title{
Transformational Leadership: The Emerging Leadership Style of Successful Entrepreneurs
}

\author{
Nerisa N. Paladan \\ Ateneo de Naga University, Naga City, Philippines
}

\begin{abstract}
This research was conducted to identify the emerging leadership style being practiced by successful entrepreneurs and the leadership behavior they frequently applied. Since, leadership style and behavior has a huge influence to the success of the entrepreneur's enterprise. One hundred and fifty (150) successful entrepreneurs was the respondent of this study and they were survey and interviewed about their actual leadership style and practices. The research design was qualitative-descriptive type of research with the use of the Multifactor Leadership Questionnaire 5X (MLQ 5X) as the survey instrument to collect data regarding leadership styles of successful entrepreneurs. An interview guide questions was likewise utilized for validating the result of the study. An in-depth semi-structured interview was also conducted to 30 entrepreneurs from the 150 respondents. Findings of the study revealed that a successful entrepreneur exhibits a noticeably higher inclination toward transformational leadership and they consistently rated themselves higher in inspirational motivation for their leadership behavior. Therefore, the emerging leadership style of successful entrepreneurs is the transformational leadership and the leadership behavior that they frequently use is the inspirational motivation. Furthermore, the aimed of this study is to explore practices of transformational leadership behavior of successful entrepreneurs from entrepreneur's perspective.
\end{abstract}

Keywords: transformational leadership, emerging leadership style, successful entrepreneurs

\section{Introduction}

Leadership becomes an important contributor to the entrepreneurial success of entrepreneurs (Arham, Boucher, \& Muenjohn, 2013). In managing the enterprise, the entrepreneur is considered the leader who influences and motivates his worker to help the enterprise achieve its goals. Northouse (2007) define leadership as a process of how to influence people and guide them to achieve organizational goals.

The performance of organizations depends on the leadership styles of the leader stated by Stahl (2007) and Ireland and Hitt (2005). This is also applicable to entrepreneur who leads his enterprise. There are many empirical researchers that have quantified the relationship between leadership and organizational performance or success, in large and small firms (Arham et al., 2013). Abdul Razak (2010) ${ }^{1}$ recommended that an increase of good leadership is one of the dynamic forces for the success of SMEs in the future and data implied that poor

Nerisa N. Paladan, D.B.A., Department of Business Management, Ateneo de Naga University.

1 Abdul Razak, M. N. (2010). Keynote address by the Honorary Prime Minister at Invest Malaysia 2010, Kuala Lumpur. 
leadership and management skills as crucial factors contributing towards the failure of SMEs (Davies, Hides, \& Powell, 2002).

Hayat and Riaz (2011) stated that transformational and transactional leadership behaviors are related to SMEs as they are directly associated to SME's business approaches and the environment in which entrepreneurs operate. This is supported by the researchers who also recommended that these leadership behaviors are more applicable to the context of SME business environment (Hayat \& Riaz, 2011; Matzler, Schwarz, Deutinger, \& Harms, 2008; Ling, Lubatkin, Simsek, \& Veiga, 2008). Zhu, Chew, and Spangler (2005) claimed that transformational leadership was positively connected to organizational performances and the chief executive officers seize a crucial role in the firm's success.

The objective of this study is to recognize the leadership style practiced by successful Filipino entrepreneurs and the leadership behavior they frequently applied. Since, leadership style and behavior has a great influence to the success of the entrepreneur's enterprise. Valdiserri and Wilson (2010) postulated that leadership style is critical to the success of a small business. Furthermore, this study illustrated how the successful Filipino entrepreneurs utilized the transformational leadership behaviors. In the Philippines, according to Calsado (2002), micro or small enterprise is starting seed and the ground from which the larger business evolves. SME's are so vital to the national economy, especially in generating employment. This study may add to the body of knowledge in the discipline of leadership and inspired other entrepreneurs on their leadership style and behavior to improve continued existence and growth rate of their enterprise.

\section{Literature Review}

\section{Leadership}

Leadership was define as "the process of influencing a group towards the achievements of goals" and a leader "someone who can influence others and who has managerial authority" (Robbins \& Coultar, 2005). According to Ensley, Pearce, and Hmieleski (2006), once an entrepreneur starts a new venture they are required to show leadership. There is an increased attention for leadership in entrepreneurship research as a result of the discovery of the fact that entrepreneurs cannot successfully develop new venture without displaying effective leadership behavior (Bryant, 2004; Cogliser \& Brigham, 2004).

\section{Full-range Leadership Theory}

The most recent model of transformational leadership is the full-range theory. The full-range model has been deemed more successful in determining effective leadership because it is an integrative theory that (1) has been widely accepted in leadership literatures, (2) is supported by empirical research, and (3) is integrative. Transactional leadership is important to effective leadership; leaders should utilize both transformational and transactional behaviors (Dum Dum, Lowe, \& Avolio, 2002). Bass argues that transactional leadership is effective in the designation of objectives and measurement of achievement; however, this style of leadership in itself is limiting. Transformational leadership is necessary to provide a higher meaning and purpose (Antonakis \& House, 2002).

Transformational leaders encourage superior results from followers by using a full-range of leadership, which is composed of one or more of the following components or behaviors (Antonakis \& House, 2002; Barnett \& McCormick, 2004). Transformational leadership includes the following five behaviors: First, the Idealized 
influence (attributed), also referred to as attributed charisma, and describes followers' perception of the leader's power, confidence, and inspirational ideals. This emotional aspect of leadership is credited with shifting follower self-interest to a global perspective that places the welfare of the organization first. Second, the Idealized influence (behaviors), also referred to as behavioral charisma, and includes leader behaviors that reveal the leader's values and beliefs, ethical and moral values, and vision. This type of leader models appropriate behavior for followers. Power is used only when necessary and never for personal gain. Third, the Inspirational motivation encourages followers to excel. Followers are motivated to achieve objectives that have previously been thought unattainable. The leader raises expectations and communicates confidence in followers that encourages the achievement of ambitious goals. Enthusiasm and optimism are results of this leadership behavior. Forth, the Intellectual stimulation encourages followers to question assumptions, invites creative solutions to problems, and challenges the status quo. Leaders encourage creative and innovative thinking and reframe problems in order to gain new perspectives. Furthermore, the leader does not publicly criticize follower's mistakes. Followers are encouraged to try new approaches and have the right to fail. Lastly, the Individualized consideration refers to leaders who act as mentors and pay attention to individual needs for growth and achievement. The leader encourages followers to strive for higher levels of attainment by pursuing challenges. This leader listens, delegates tasks as a means of developing followers, and offers direction or support as needed.

In summary, leadership is one of the important factors that affect the success of the entrepreneurs. Thus, entrepreneurs must develop a deeper understanding of leadership style and behavior to facilitate the achievement of their enterprise goals and objectives.

\section{Methodology}

The respondents of this study was the top 25 successful Filipino entrepreneurs from the six provinces of Bicol region, who directly managed their enterprise and engaged in small and medium scale enterprises, a total of 150 respondents. The respondents were identified, selected, and recommended by the provincial office of Department of Trade and Industry (DTI) from Bicol region, this office is responsible in monitoring the performance of the SMEs. The basis for the top 25 successful entrepreneurs per six provinces was the total sales and total assets of the enterprise.

The study adopted qualitative-descriptive type of research, a descriptive research which used the Multifactor Leadership Questionnaire 5X (MLQ 5X) as the survey instrument to collect data regarding leadership styles of successful entrepreneurs. An interview guide questions was likewise utilized for validating the result of the study. Furthermore, an in-depth semi-structured interview was also conducted to 30 entrepreneurs that collected data on how the successful entrepreneurs utilized transformational leadership behavior in managing their enterprises and also provide a narrative explanation of their leadership practices.

The aimed of this study is to explore practices of transformational leadership behavior of successful entrepreneurs from entrepreneur's perspective and to better understand it, rather than testing any model or hypothesis. Therefore, qualitative approach is undertaken (Patton, 2002). This study also includes synthesizing the information obtained from various sources like interviews and documents into a coherent description of what was discovered; which are part of a qualitative research. 


\section{Findings and Discussions}

\section{Emerging Leadership Style of Successful Entrepreneurs}

From the survey of 150 respondents' of this study using MLQ questionnaires indicates that $38 \%$ of the respondents are fairly often utilizing transformational leadership style and $36 \%$ frequently if not always. Successful entrepreneurs believe that using this style of leadership has a great impact to the success of their enterprise. That a follower achieved better results under transformational leaders than other types of leadership style (Dvir, Eden, Avolio, \& Shamir, 2002) and there is a significant positive relationship between transformational leadership and performance (Roslan, Rosli, Mohd Hussin, \& Anas, 2013), that leads to the success of the enterprise. Furthermore, among the leadership style, transformational leadership is the best predictor of business performance (Gardner \& Stough, 2002) and this is the reason why successful entrepreneurs make use of this leadership style.

Only $6 \%$ are not at all making use of transformational leadership style and $5 \%$ once in while. These are the entrepreneur that has other form of leadership style but also recognized the importance of transformational leadership. Some of the entrepreneurs also applied the transaction leadership style in some of the situation they encounter in managing their enterprise.

In Figure 2, it indicates 19\% are frequently if not always making use of transactional leadership style and $25 \%$ are not at all. Successful entrepreneurs believe that from time to time transactional leadership style is needed in managing their enterprise. Since the operations of their enterprise are transactional in nature. According to entrepreneurs this leadership style is required to address coherent needs especially in the early stage of their business, like the establishing performance expectations and clarification of rewards contingencies in order to influence performance of individual behavior to realize the enterprise objectives (Ensley et al., 2006).

Looking at Figures 1 and 2, there are 36\% frequently if not always utilizing transformational leadership style and 19\% frequently if not always make use of transactional leadership style. Therefore, the emerging leadership style of successful entrepreneurs is more of transformational leadership. This is supported by the study of George and Jones (2005) that an entrepreneur thereby reflects the attributes of transformational leadership. According to M. Sundararajan, B. Sundararajan, and Herderson (2012) among the leadership models, transformational style is applicable when the entrepreneur engages in communicating long-term vision, inspiration, deeper meaning (Conger, 1989), entrepreneurial endeavors (Burns, 1978), as well as initiations critical to the growth of a new firm (Baglia \& Hunt, 1988). Also, Thornberry (2006) asserts that entrepreneurial leadership is more like transformational leadership than it is like transactional leadership, yet it differs in some fundamental ways.

In Figure 3, it shows the transformational leadership behavior of successful Filipino entrepreneurs, 23\% of the entrepreneurs frequently use the inspirational motivation leadership behavior followed by idealized influence behavior which is $22 \%$ who make use of it, $20 \%$ of the entrepreneurs employed individual consideration and intellectual stimulation leadership behavior. Therefore, the transformational leadership behavior that is frequently use by successful Filipino entrepreneur is the inspirational leadership behavior. 


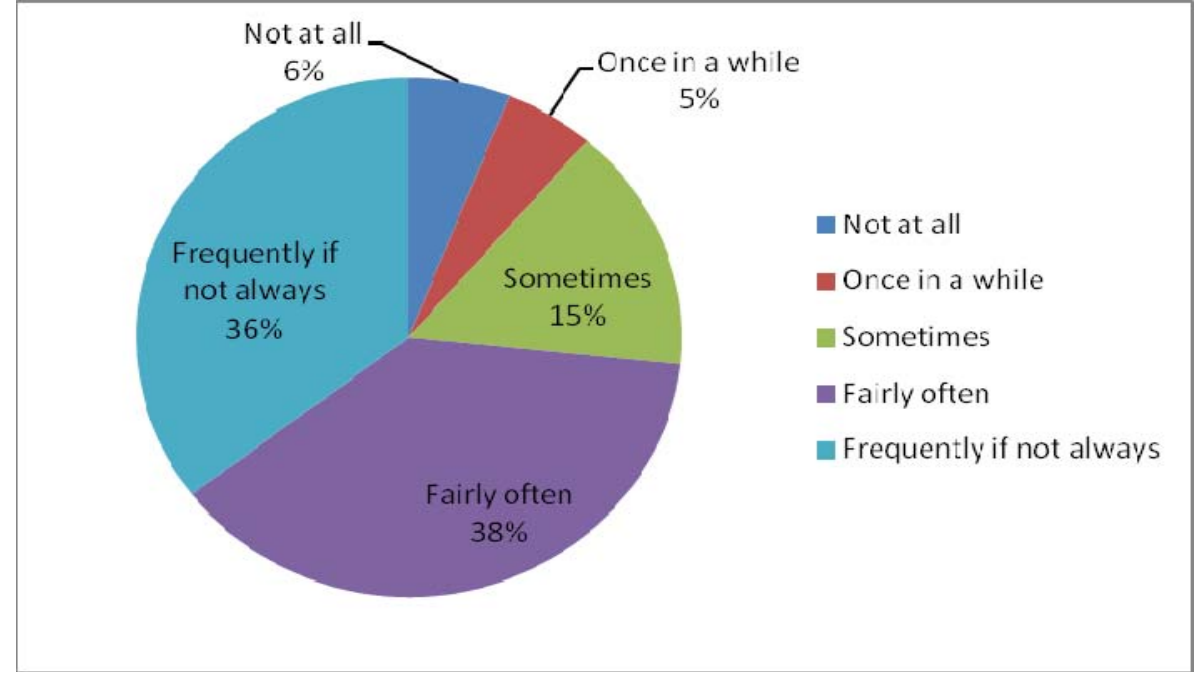

Figure 1. Frequency of utilizing transformational leadership style.

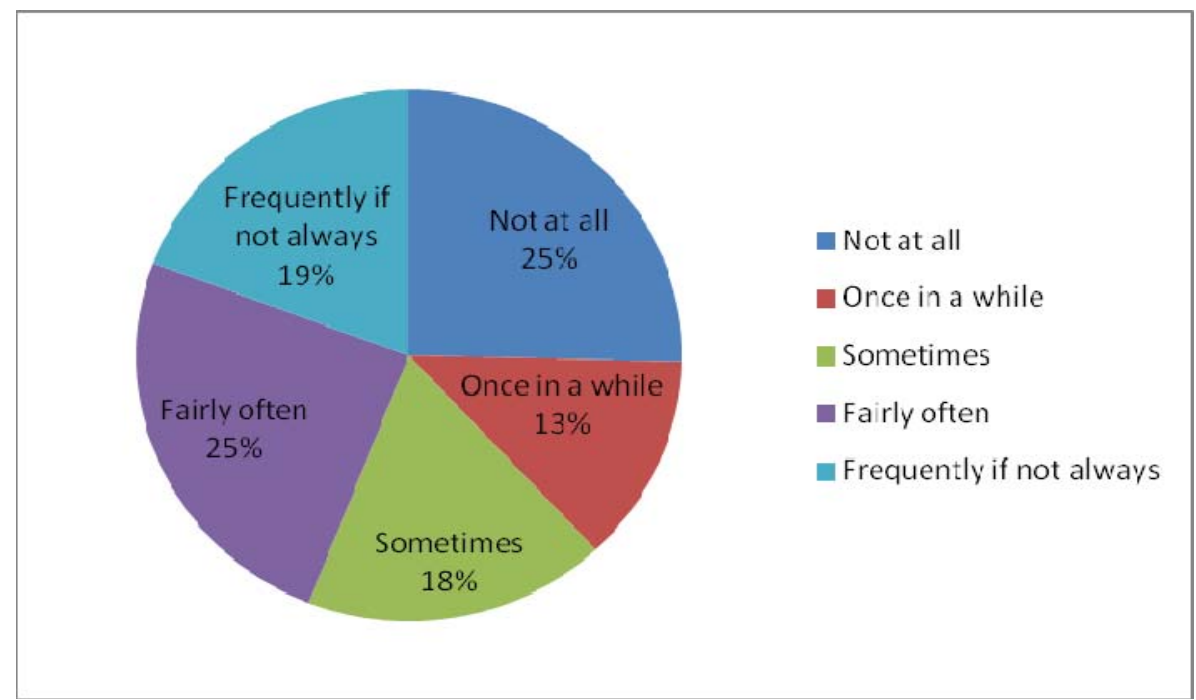

Figure 2. Frequency of utilizing transactional leadership style.

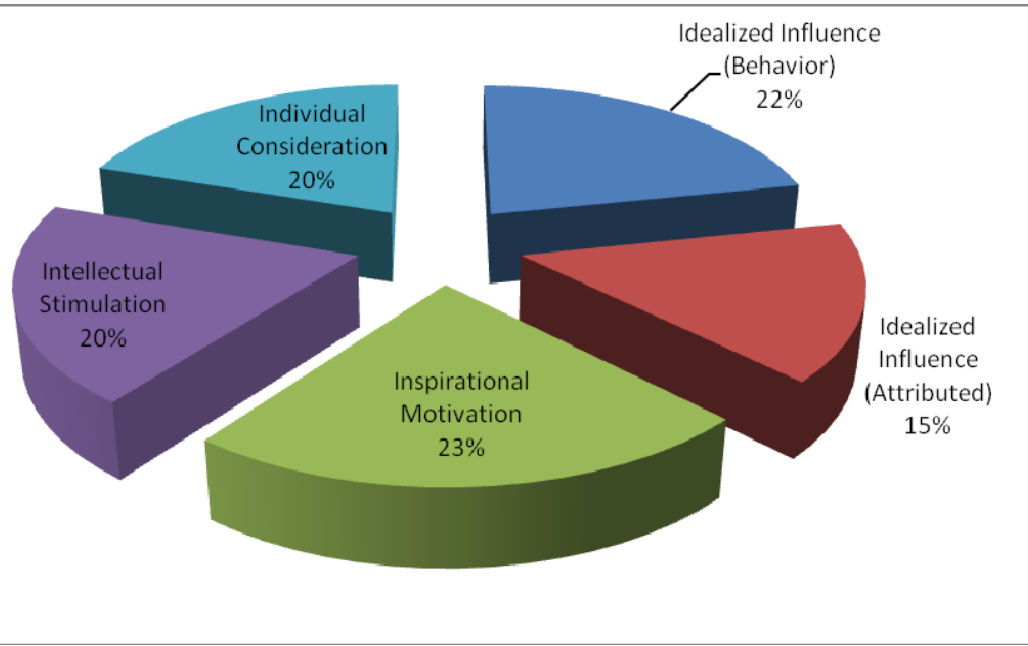

Figure 3. Frequency of utilizing the transformational leadership behavior. 
Transformational leadership is a new and popular emerging leadership style which seems to be ideal style of leadership for the successful entrepreneurs. This leadership style is concern on values of the interaction between entrepreneurs which is the leader and their employees as a strong team. Moreover, this leadership style makes an assumption that entrepreneurs which are the leader inspire the team with vision and give direction by motivating and encouraging the employees to achieve the enterprise goals.

\section{Transformational Leadership Behavior of Successful Entrepreneurs}

In-depth, semi-structured interview was conducted to a 30 successful entrepreneurs. The aim of the interview is to ask the 30 successful entrepreneurs how they utilized the transformational leadership behavior in managing the day to day operation of their enterprise.

There are five leadership behaviors in transformational leadership style and two questions were asked for each leadership behavior. Below are the questions for each leadership behavior and the responses of the 30 successful entrepreneurs:

Inspirational motivator. The questions asked were as followed: How do you articulate the compelling vision of your enterprise? And, how do you share to your employees the future plan of your enterprise? Their responses were:

I demonstrate and tell to my people that the vision of my enterprise is to earn profit and to provide stable livelihood to the people in my local community. I illustrate this in an informal way, through my actions and conversation. As a result, employees in my enterprise develop their initiative to care for the business because whatever happens to my enterprise, their livelihood will also be affected.

I shared to my employees the future plan of my enterprise through formal, informal meetings and general assemblies. In the meetings I tell my people the short term and long term plan of the enterprise, and then seek for their suggestions. I ask my employees on what they can contribute to achieve those plans because I value the participation of my people. This develops the team spirit of my employees believing that they are valued in my enterprise thus they are encouraged to work together and do their best on whatever task they were assigned, and help my enterprise realize its future plan.

Successful entrepreneurs utilized inspirational motivator leadership behavior by formulating, inspiring, and sharing the vision and future plans of their enterprise to their employees. Furthermore, entrepreneurs as transformational leaders, broaden and elevate the interests of their employees, generate awareness and acceptance of their enterprise's purpose and mission, and motivate their employees to look beyond their own self-interests to the good of others (Schermerhorn, Jr., Hunt, \& Osborn, 2005).

Idealized influencer of behavior. The questions asked were as followed: How do you share the most important values and beliefs of your enterprise? And, how do you specify the importance of having a strong sense of purpose to your employees? Their responses were:

I shared the most important values and belief of my enterprise when I provide livelihood to marginalized people and help them grow financially and develop their right attitude towards spending. Another is when I emphasize to my employees the value of hardwork and perseverance. Then, when I valued my people who produce the quality product of my enterprise, I consider them as partners in my business. Lastly, I lead by example to my people.

I specify the importance of having a strong sense of purpose to my employees in the course of the following: first, I encourage them to produce quality goods because this will benefit the enterprise and also the employees; second, I provide positive attitude to my employees; third, I inspire my employees to work as a team because as enterprise grow, employees would have a better livelihood opportunity; and lastly, I identify employees’ need and provide it. 
This leadership behavior of successful entrepreneurs is supported by the study of Hood (2003) that indicates transformational leaders would go beyond simple legal prescription and take a more voluntary socially responsible and ethical stance within the enterprise.

Idealized influencer of attribute. The questions asked were as followed: Do you display a sense of power and confidence in managing your enterprise? How? And, do you instill pride to your employees for being associated to your enterprise? How? Why? Their responses were:

I display a sense of power and confidence in managing my enterprise through the following: first, I'm firm in making decisions and show to my employees that I'm capable of managing the problems of the enterprise; second, I am also firm in giving instruction and I'm systematic; third, I personally deal with my customers and employees; forth, I'm strict in terms of working issues but maintain a good working relationship with my employees; and lastly, I show trust to my employees, affirm them in their small accomplishment and provide disciplinary action if necessary.

I instill pride to my employees for being associated to my enterprise. These are manifested in the following: employees' loyalty to the enterprise; valuing the camaraderie that they have; boosting their morale by giving them a chance to work in the company; providing conducive working environment; and the transparency of the company to their customer and employees. They also believe that the enterprise is sustainable and could provide them better livelihood. These are the reasons why they work and stay for a long period of time in my enterprise.

Moreover, the entrepreneur is the one who guides the vision and direction of the enterprise which is the same as the idealized influence of transformational leadership (Matzler et al., 2008).

Intellectual stimulator. The questions asked were as followed: How do you encourage the employees to look for new ways to complete their task? And, how do you encourage the employees to analyze problems encountered by the enterprise in different perspective? Their responses were:

I encourage my employees to look for new ways to complete their task in the course of the following: first, I affirm my employees in their work and make suggestions on how they could improve the accomplishment of their task; second, I conduct a dialog with my employees in a two-way communication process which aims to develop self-awareness in my employees; and lastly, I set target date to accomplish the task assigned to my employees and provide close supervision.

I encourage the employees to analyze problems of my enterprise in different perspective and to re-examine the critical assumptions to problems whether they are appropriate or not, through open communication and transparency. I'm open and transparent to my employee on what is happening to the enterprise, the demand for the product, its financial status and competition in the market and I ask for their suggestions and opinion.

Entrepreneurs believe that the participation of employees in solving problems of the enterprise will benefit both parties.

Individual considerer. The questions asked were as followed: Do you spend time in teaching and coaching your employees to accomplish their task? How? Why? And, how do you help your employees develop their strength? Their responses were:

I spend time in teaching and coaching my employees to accomplish their task through the following: first, I'm hands-on to the task assigned to my employees. Thus I show to the employees how to do it and personally guide them; second, I also provide close supervision to my employees where one on one coaching happens; and lastly, I allow my employees to attend trainings to help upgrade and update their skills.

I help my employees develop their strength on the first time that they are assigned to a particular task where they are good at to develop their mastery. Next, I have this job rotation to give my employees the opportunity to do different tasks and develop their other skills. Another thing is I allow my employees to attend seminars, trainings and trade fairs offered 
by the DTI to help them boost their morale and develop their self esteem. Lastly, I'm consistent in motivating employees to do their best.

Generally, transformational leadership occurs when an entrepreneur helps transform their employees in a vital way that contributes to the higher level of performance behavior of employees and trust to the entrepreneurs that both lead to the achievement of the enterprise goals.

\section{Conclusion}

Leadership is one of the significant factors that have an influence to the success of the entrepreneurs. Thus, entrepreneurs must widen a deeper understanding of leadership style and behavior to ease the achievement of the enterprise goals and objectives. The objective of this study is to recognize the leadership style being practiced by successful Filipino entrepreneurs and the leadership behavior they frequently applied.

The study used an instrument based on a contemporary full-range leadership model to distinguish and determine the specific leadership characteristics of successful Filipino entrepreneurs. A successful Filipino entrepreneur exhibits a noticeably higher inclination toward transformational leadership and they consistently rated themselves higher in inspirational motivation for their leadership behavior. Therefore, the emerging leadership style of successful Filipino entrepreneurs is the transformational leadership and the leadership behavior that they frequently use is the inspirational motivation.

Entrepreneur's transformational leadership practices include sharing and inspiring the vision of their enterprise to their employees, and instilling the values and belief of their enterprise to their employees. Entrepreneurs need to display sense of power and confidence in managing their enterprise to build respect and pride to their employee being associated to their enterprise. Also encouraging employees to look for new ways to accomplish their task and analyze problems. Lastly, entrepreneurs also engaged their self in teaching, coaching, and developing the strength of their employees.

\section{References}

Antonakis, J., \& House, R. J. (2002). The full-range leadership theory: The way forward. In B. J. Avolio, \& F. J. Yammarino (Eds.), Transformational and charismatic leadership (pp. 3-33). Boston: JAI Press.

Arham, A. F., Boucher, C., \& Muenjohn, N. (2013). Leadership and entrepreneurial success: A study of SMEs in Malaysia. World Journal of Social Sciences, 3(5), 117-130.

Baglia, B. R., \& Hunt, J. G. (1988). An organizational life cycle approach to leadership. In J. G. Hunt, B. R. Baliga, H. P. Dachler, \& C. A. Schriesheim (Eds.), Emerging leadership (pp. 129-149). Lexington, MA: Health.

Barnett, K., \& McCormick, J. (2004). Leadership and individual principal-teacher relationships in schools. Educational Administration Quarterly, 40(3), 406-434.

Bryant, T. A. (2004). Entrepreneurship. In G. R. Goethals, G. J. Sorenson, \& J. M. Burns (Eds.), Encyclopedia of leadership (pp. 442-448). Thousand Oaks, CA: Sage.

Burns, J. M. (1978). Leadership. New York: Harper and Row.

Calsado, T. (2002). Women-run Small and Medium Scale Enterprise (SMEs) gaining strength to succeed in the global economy. Retrieved from http://winner-tips.org/magazines/women-run-small-and-medium-scale-enterprises-smes-gaining-strength-to-succeed-in-the-g lobal-economy/

Cogliser, C. C., \& Brigham, K. H. (2004). The intersection of leadership and entrepreneurship: Mutual lessons to be learned. The Leadership Quarterly, 15(6), 771-799.

Conger, J. A. (1989). Leadership: The art of empowering others. Academy of Management Executive, 3, 471-482. 
Davies, J., Hides, M., \& Powell, J. (2002). Defining the development needs of entrepreneurs in SMEs. Education + Training, 44(8/9), 406-412.

Dum Dum, R., Lowe, K. B., \& Avolio, B. J. (2002). A meta-analysis of transformational and transactional leadership correlates of effectiveness and satisfaction: An update and extension. In B. J. Avolio, \& F. J. Yammarino (Eds.), Transformational and charismatic leadership: The road ahead (pp. 35-66). Oxford, UK: Elsevier Science.

Dvir, T., Eden, D., Avolio, B. J., \& Shamir, B. (2002). Impact of transformational leadership on follower development and performance: A field experiment. Academy of Management Journal, 45(4), 735-744.

Ensley, M. D., Pearce, L. C., \& Hmieleski, M. K. (2006). The moderating effect of environmental dynamism on the relationship between entrepreneur leadership behavior and new venture performance. Journal of Business Venturing, 21, 243-263.

Gardner, L., \& Stough, C. (2002). Examining the relationship between leadership and emotional intelligence in senior level managers. Leadership and Organization Development Journal, 23(1-2), 68-78.

George, J., \& Jones, G. (2005). Understanding and managing organizational behavior (4th ed.). Upper Saddle River, NJ: Pearson Prentice Hall.

Hayat, N., \& Riaz, M. T. (2011). “The influence of the SMEs top level managers” leadership styles and their entrepreneurial orientation on the business performance. Retrieved from http://ssrn.com/abstract=1884069

Hood, J. N. (2003). The relationship of leadership style and CEO values to ethical practices in organizations. Journal of Business Ethics, 43, 263-273.

Ireland, R. D., \& Hitt, M. A. (2005). Achieving and maintaining strategic competitiveness in the 21st century: The role of strategic leadership. Academy of Management Executive, 19(4), 63-77.

Ling, Y., Lubatkin, M. H., Simsek, Z., \& Veiga, J. F. (2008). The impact of transformational CEOs on the performance of small-to-medium-sized firms: Does organizational context matter? Journal of Applied Psychology, 93(4), 923-934.

Matzler, K., Schwarz, E., Deutinger, N., \& Harms, R. (2008). Relationship between transformational leadership, product innovation and performance in SMEs. Journal of Small Business and Entrepreneurship, 21(2), 139-152.

Northouse, P. G. (2007). Leadership: Theory and practice (4th ed.). London: Sage Publications.

Patton, M. (2002). Qualitative research and evaluation methods. Thousand Oaks, California: Sage Publications.

Robbins, S. P., \& Coultar, M. (2005). Management (8th ed.). NJ: Pearson Education, Inc.

Roslan, A. A., Rosli, M., Mohd Hussin, A., \& Anas, T. (2013). The effect of leadership styles on the business performance of SMEs in Malaysia. International Journal of Economics Business and Management Studies, 2(2), 45-52.

Schermerhorn, J. R., Jr., Hunt, J. G., \& Osborn, R. N. (2005). Organizational behavior (9th ed.). Hoboken, NJ: John Wiley \& Sons, Inc.

Stahl, M. J. (2007). The influential leader. Leader to Leader, 46, 49.

Sundararajan, M., Sundararajan, B., \& Herderson, S. (2012). Role of meditative foundation entrepreneurial leadership and new venture success. Journal of Spirituality, Leadership and Management, 6(1), 59-70.

Thornberry, N. (2006). Lead like an entrepreneur. Blacklick, OH: McGraw-Hill.

Valdiserri, G. A., \& Wilson, J. L. (2010). The study of leadership in small business organizations: Impact on profitability and organizational success. The Entrepreneurial Executive, 15, 47-71.

Zhu, W., Chew, K. H., \& Spangler, W. D. (2005). CEO transformational leadership an organizational outcomes: The mediating role of human capital enhancing human resource management. The Leadership Quarterly, 19, 39-52. 